\title{
Modeling of hydrogen bonds in molecular alanine crystals
}

\author{
(C) Tatiana G. Volkova, ${ }^{1 *}$ Aygul N. Shajayewa, ${ }^{1}$ and Irina O. Talanova ${ }^{2+}$ \\ ${ }^{1}$ Department of Organic and Physical Chemistry. Ivanovo State University. \\ Ermak St., 39. Ivanovo, 153025. Russia.E-mail:tgvolkova@yandex.ru \\ ${ }^{2}$ Department of Biochemistry. Ivanovo State Medical Academy. \\ Sheremetevsky pr., 8.Ivanovo, 153012.Russia.E-mail: i75@list.ru
}

\begin{abstract}
*Supervising author; ${ }^{+}$Corresponding author Keywords: amino acids, alanine, hydrogen bonding, intermolecular interaction, modeling.
\end{abstract}

\begin{abstract}
The study of hydrogen bonds (H-bonds) in biomolecules and living systems is currently one of the most urgent tasks. Changes in the structure of molecular crystals associated with h-bond instability may affect the state of drugs due to uncontrolled polymorphic transformations. Quantum chemical modeling is one of the methods for studying the nature and determining the strength of hydrogen bonds. The interaction energy in molecular alanine crystals and its decomposition were calculated using the Morokuma method (HF/6-31G (PC GAMESS)). The estimation of such energy components as electrostatic, repulsion exchange, polarization, charge transfer, and mixing is given. It is shown that for four model systems, the electrostatic component makes the main contribution to the interaction energy, and the trend of distribution of components $\Delta \mathrm{E}$ by values is the same for them. For the two model systems, there is a significant difference from the others both in the amount of interaction energy and in the distribution of individual energy components. The difference in the interaction energy and in the values of its components indicates a difference in the nature of hydrogen bonds in the studied associate. In four models, the H-bond system is the result of electrostatic interaction (Ees and Ect are respectively equal to -41.0 and $-6.84 \mathrm{kcal} / \mathrm{mol}$ ), and in two-the proportion of covalent interaction is significantly greater (Ees $=-7.94 \mathrm{kcal} / \mathrm{mol}$ and $\mathrm{Ect}=-3.92 \mathrm{kcal} / \mathrm{mol}$ ). The comparison of data allows us to conclude that there are three types of hydrogen bonds in the molecular crystal of alanine that differ from each other in energy characteristics.
\end{abstract}

\section{References}

[1] I.S. Chekman, A.O. Syrovaya, I.V. Novikova, V.A. Makarov, S.V. Andreeva, L.G. Shapoval. Amino acids - nanoscale molecules: clinical and laboratory studies. Kharkov. 2014. 154p.

[2] E. Boldyreva. Physical pharmacy and its capabilities. Science in Russia. 2014. Vol.201. No.3. P.26-35. (russian)

[3] Cambridge Crystallographic Date Centre (CCDC): http://www.ccdc.com.ac.uk

[4] A.M.R. Teixeira, P.T.C. Freire, A.J.D. Moreno, J.M. Sasaki, A.P. Ayala, F.J. Mendes, F.E.A. Melo. High-pressure Raman study of L-alanine crystal. Solid State Commun. 2000. Vol.116. P.405-409.

[5] C.C. Wilson, D. Myles, M. Goshh, L.N. Johnson, W. Wang. Neutron diffraction investigations of L-and D-alanine at different temperatures: the search for structural evidence for parity violation. New J. Chem. 2005. Vol.29. P.1318-1322.

[6] J.S. Olsen, L. Gerward, A.G. Souza, P.T.C. Freire, J. Mendes, F.E.A. Melo. High Pressure X-Ray Diffraction of $L$-alanine Crystal. High Pressure Research. 2006. Vol.26. P.433-437.

[7] J.S. Olsen, L. Gerward, P.T.C. Freire, M. Filho. Pressure-induced Phase Transformation in L-Alanine Crystals. J. Phys. Chem. Solids. 2008. Vol.69. P.1641-1645.

[8] N.A. Tumanov, E.V. Boldyreva, B.A. Kolesov, A.V. Kurnosov, R.Q. Cabrera. Pressure-induced phase transitions in $L$-alanine, revisited. Acta Cryst. 2010. Vol.B66. P.458-471.

[9] A.A. Granovsky. PCGAMESS version 7.1. http://classic.chem.msu.su/gran/gamess/index.html.

[10] K. Morokuma, K. Kitaura. A new energy decomposition scheme for molecular interactions within the Hartree-Fock approximation. International Journal of Quantum Chemistry. 1976. Vol.X. P.325-327.

[11] K. Morokuma. Molecular Orbital Studies of Hydrogen Bonds. III. $\mathrm{C}=\mathrm{O} \cdots \mathrm{H}-\mathrm{O}$ Hydrogen Bond in $\mathrm{H}_{2} \mathrm{CO} \cdots \mathrm{H}_{2} \mathrm{O}$ and $\mathrm{H}_{2} \mathrm{CO} \cdots 2 \mathrm{H}_{2} \mathrm{O}$. J. Chem. Phys. 1971. Vol.55. P.1236-1244. 